\title{
Perinatal Mental Health in Kashmir, India During The COVID-19 Pandemic
}

\author{
Sheikh Shoib ${ }^{1}$ (1) . S. M. Yasir Arafat ${ }^{2} \cdot$ Waleed Ahmad $^{3}$
}

Published online: 9 September 2020

(c) Springer Science+Business Media, LLC, part of Springer Nature 2020

\begin{abstract}
The current COVID-19 pandemic in Kashmir along with lockdown measures—ordered to prevent the spread of the disease- - has added further trauma to the fragile mental health system in Kashmir. There may be unquantifiable repercussions of the current epidemic on the emotional status of women during the perinatal period. There are numerous challenges in the perinatal period arising out of COVID-19 directly or indirectly because of lockdown measures that has been put in place to prevent the spread of disease.
\end{abstract}

Keywords Covid 19 P Perinatal mental health · Jammu and kashmir

COVID-19, the disease caused by the novel Severe Acute Respiratory Syndrome Coronavirus-2 (SARS-CoV2), has spread to nearly all regions across the globe, including the territory of Jammu and Kashmir. Psychological health problems are increasingly being recognized as a significant secondary effect of the COVID-19 pandemic (Pfefferbaum and North 2020). An administrative lockdown shortly preceded the current COVID-19 pandemic in Kashmir. Lockdown measures were taken to prevent the spread of the disease, adding to the trauma of the fragile mental health system of Kashmir-especially women in the perinatal period.

Several factors increase the risk of mental illness in the perinatal period, irrespective of external events. These factors include genetic vulnerability, hormonal and immunological factors, and the sleep disturbances associated with delivery (Harrison et al. 2017). There are numerous challenges in the perinatal period arising out of COVID19 directly or indirectly because of the lockdown measures undertaken to prevent the spread of disease. The factors

Sheikh Shoib

sheikhshoib22@gmail.com

1 Department of Psychiatry, Jawahar Lal Nehru Memorial Hospital (JLNMH), Rainawari, Srinagar, Jammu and Kashmir 190003, India

2 Department of Psychiatry, Enam Medical College and Hospital, Dhaka 1340, Bangladesh

3 Department of Psychiatry and Behavioural Science, Peshwar Medical College, Peshawar, Khyber Pakhtunkhwa, Pakistan that can significantly increase the risk of perinatal mental health problems during a pandemic are maternal isolation, increased psychosocial risk during a socio-economic crisis, increased maternal anxiety, relationship conflicts, and decreased contact with healthcare professionals (Thapa et al. 2020). The structure of the labour and delivery rooms has changed, and the subsequent isolation of women in the wards has led to psychological effects on pregnant women. As such, there could be unquantifiable repercussions of the current epidemic on the emotional status of the women around the perinatal period (Cameron et al. 2020). Mother-infant proximity has been affected during this pandemic and the World Health Organization advocates consideration of the clinical status of the woman while deciding (WHO 2019). These unforeseen consequences because of the pandemic may have unintended long-term devastating effects on women and families and lead to exacerbation of mental health issues, postpartum depression (Torales 2020). However, most women who test positive for COVID-19 exhibit mild symptoms and recover well. The lockdown measures and its subsequent impacts have increased loneliness and disrupted the economy, which has directly or indirectly affected prenatal and postnatal support services. Keeping in view these facts, we advocate a need for supplementing the healthcare staff with mental health staff in the perinatal setting. Also, psychological and socio-behavioral research needs to be carried out to fill the knowledge gaps about the effect of COVID-19 on pregnancy and perinatal health. We are yet to know about the short- and long-term implications 
on the mental well-being of a woman and her infant following their experiences of maternity during a pandemic. There seems to be a wide gap in our knowledge of optimal maternity care.

The percentage of institutional deliveries in Srinagar is high (97.4\%), with 2.6\% home deliveries (Rather et al 2017). COVID-19 influenced the management of perinatal psychiatric conditions in Kashmir. Anxiety and depression during pregnancy are major public health issues, however they often remains unrecognized. The fear and anxiety regarding COVID-19 can affect the outcome of pregnancy and neonatal health due to increased maternal stresses and that may cause increased risk of preterm delivery, postnatal complications, and low birth weight (Castro et al. 2020). Increased stress in pregnant women could interfere with neurodevelopment of the fetus which could pose a risk of psychiatric illness (Abbott et al. 2018). Further, stress could cause puerperal complication such as post-partum depression and poor parental bonding (Upadhyay et al. 2017). During the COVID-19 pandemic, pregnant women in Kashmir are experiencing psychological distress due to disruption in prenatal services and reduced access to health care for themselves and their newborn. The liaison of psychiatry with maternal and child care services in Kashmir is further complicated by decrease in access to mental health services and inadequate tele-psychiatric services due to communication blackouts. There is a major challenge in detecting maternal mental health issues; maternal mental health services are largely deficient in Kashmir and health care workers lack mental health training. There is great shortage of mental health professionals, especially in periphery health care. The lockdown measures imposed by authorities have denied access to psychiatric diagnosis and treatment in the face of a COVID-19 emergency. In Kashmir, the Government effectuated proactive measures toward psychological distress among the public, though preparation and planning for the mental health impact of the pandemic was lacking. Additionally, Kashmir experiences a major shortage of mental health professionals to affect the delivery of maternal health services and may widen the treatment gap for mental disorders (Ransing et al. 2020). Although changing trends in social fabrics restrict our alternative modes of care and rearing for this vulnerable group, it should not deter us from exploring through scientific research and finding remedial measures to mitigate their suffering. In the backdrop of events such as the COVID-19, we must recognize the potential for adverse perinatal mental health consequences as a critical public health concern, together with care and support to prevent and ameliorate its negative effects.
Funding The authors received no financial support for the research, authorship, and /or publication of this article.

\section{Compliance with Ethical Standards}

Conflict of interest The authors declared no potential conflicts of interest with respect to the research, authorship, and /or publication of this article.

\section{References}

Abbott, P. W., Gumusoglu, S. B., Bittle, J., Beversdorf, D. Q., \& Stevens, H. E. (2018). Prenatal stress and genetic risk: how prenatal stress interacts with genetics to alter risk for psychiatric illness. Psychoneuroendocrinology, 90, 9-21.

Cameron, E., Joyce, K., Delaquis, C., Reynolds, K., Protudjer, J., \& Roos, L. E. (2020). Maternal psychological distress \& mental health services use during the COVID-19 pandemic. Journal of Affective Disoreders. https://doi.org/10.31234/osf.io/a53zb.

Castro, P., Narciso, C., Matos, A. P., Werner, H., \& Araujo Júnior, E. (2020). Pregnant, uninfected, stressed, and confined in the COVID-19 period: what can we expect in the near future? Revista da Associação Médica Brasileira, 66(4), 386-387.

Harrison, P. J., Cowen, P., Burns, T., \& Fazel, M. (2017). Shorter Oxford textbook of psychiatry. Oxford: Oxford University Press.

Pfefferbaum, B., \& North, C. S. (2020). Mental health and the Covid19 pandemic. New England Journal of Medicine. https://doi. org/10.1056/NEJMp2008017.

Ransing, R. S., Agrawal, G., Bagul, K., \& Pevekar, K. (2020). Inequity in distribution of psychiatry trainee seats and institutes across Indian states: a critical analysis. Journal of Neurosciences in Rural Practice, 11(2), 299.

Upadhyay, R. P., Chowdhury, R., Salehi, A., Sarkar, K., Singh, S. K., Sinha, B., et al. (2017). Postpartum depression in India: a systematic review and meta-analysis. Bulletin of the World Health Organization, 95(10), 706.

Rather, R. H., Nazir, U., Samreen, S., \& Itoo, M. S. (2017). Fetomaternal outcome among pregnant females in block Hazratbal of district Srinagar, Jammu and Kashmir: a prospective longitudinal study. International Journal of Community Medicine and Public Health, 4(9), 3186.

Thapa, S. B., Mainali, A., Schwank, S. E., \& Acharya, G. (2020). Maternal mental health in the time of the COVID-19 pandemic. Acta Obstetricia et Gynecologica Scandinavica. https://doi. org/10.1111/aogs.13894.

Torales, J., O’Higgins, M., Castaldelli-Maia, J. M., \& Ventriglio, A. (2020). The outbreak of COVID-19 coronavirus and its impact on global mental health. International Journal of Social Psychiatry. https://doi.org/10.1177/0020764020915212.

World Health Organization. (2020). Clinical management of severe acute respiratory infection (SARI) when COVID-19 disease is suspected: interim guidance. World Health Organization. https:// doi.org/10.15557/PiMR.2020.0003.

Publisher's Note Springer Nature remains neutral with regard to jurisdictional claims in published maps and institutional affiliations. 